\title{
The asbestos fibre burden in human lungs: new insights into the chrysotile debate
}

\author{
Inke Sabine Feder ${ }^{1}$, Iris Tischoff ${ }^{1}$, Anja Theile ${ }^{1}$, Inge Schmitz ${ }^{1}$, Rolf Merget $^{2}$ and \\ Andrea Tannapfel ${ }^{1}$
}

Affiliations: ${ }^{1}$ Institute for Pathology of the Ruhr-University Bochum, Bochum, Germany. ${ }^{2}$ Institute for Prevention and Occupational Medicine of the German Social Accident Insurance, Institute of the Ruhr-University (IPA), Bochum, Germany.

Correspondence: Inke Sabine Feder, Georgius Agricola Foundation Ruhr, Institute for Pathology of the Ruhr-University Bochum, at the BG University Hospital Bergmannsheil, German Mesothelioma Register, Bürkle-de-la-Camp Platz 1, 44789 Bochum, Germany. E-mail: Inke.federAruhr-uni-bochum.de

@ERSpublications

Intra-individual longitudinal data display: the asbestos fibre burden in living human lungs is stable over many years http://ow.ly/VtPF30bRETz

Cite this article as: Feder IS, Tischoff I, Theile A, et al. The asbestos fibre burden in human lungs: new insights into the chrysotile debate. Eur Respir J 2017; 49: 1602534 [https://doi.org/10.1183/13993003.025342016].

ABSTRACT The traceability of asbestos fibres in human lungs is a matter of discussion especially for chrysotile. This issue is of high significance for differential diagnosis, risk assessment and occupational compensation. At present no intra-individual longitudinal information is available. This study addresses the question whether the asbestos fibre burden in human lungs decreases with time after exposure cessation.

The database of the German Mesothelioma Register was screened for patients with asbestos body counts of at least 500 fibres per gram of wet lung, which had been analysed twice from different tissue excisions at minimum intervals of 4 years.

Twelve datasets with individual longitudinal information were discovered with a median interval of about 8 years (range 4-21 years). Both examinations were performed after exposure cessation (median: surgery, 9.5 years; autopsy, 22 years). Pulmonary asbestos fibre burden was stable between both examinations (median 1623/4269 asbestos bodies per gram wet lung). Electron microscopy demonstrated a preponderance of chrysotile (median $80 \%$ ).

This study is the first to present longitudinal intra-individual data about the asbestos fibre burden in living human lungs. The high biopersistence of amphiboles, but also of chrysotile, offers mechanistic explanations for fibre toxicity, especially the long latency period of asbestos-related diseases.

This article has supplementary material available from erj.ersjournals.com

Received: Dec 232016 | Accepted after revision: Feb 262017

Support statement: The Institute of Pathology gets third-party funds from the German Social Accident Insurance (DGUV) for research of the German Mesothelioma Register. Freedom to design, conduct, interpret, and publish research is not compromised by this.

Conflict of interest: Disclosures can be found alongside this article at erj.ersjournals.com

Copyright $\odot E R S$ 2017. This ERJ Open article is open access and distributed under the terms of the Creative Commons Attribution Non-Commercial Licence 4.0. 


\section{Introduction}

The major health hazards associated with asbestos are fibrogenicity and carcinogenicity, with lung cancer and mesothelioma as the main representatives. It has been shown that the risk of developing mesothelioma or lung cancer increases proportionally to the asbestos fibre burden of the lungs [1], and also the extent of pleural plaques has been found to be associated with fibre numbers in lung tissue [2]. Thus fibre clearance and biopersistence are considered the most important factors for diagnosis and risk assessment of malignant and non-malignant diseases.

The latency period from first asbestos exposure to the manifestation of an asbestos-induced disease may be 10-60 years with shorter times for asbestosis and plaques and longer times for lung cancer and mesothelioma. Thus an asbestos-related disease might occur a long time after exposure cessation. Therefore, the question of the traceability of asbestos fibres in lungs tissue after prolonged intervals is of significance, e.g. for the differentiation of asbestosis and further fibrotic lung diseases, such as idiopathic pulmonary fibrosis (IPF) $[3,4]$. In this context lung dust analysis is considered a valuable tool $[5,6]$.

Asbestos fibre analyses in the lungs of asbestos-exposed workers have a long tradition in establishing a link between exposure and disease [7]. The tissue is digested, the digestate collected on a membrane filter and fibres are counted by light microscopy, phase-contrast or scanning electron microscopy (SEM). Transmission electron microscopy (TEM) may also be used. In addition, the fibre type can be analysed with energy-dispersive X-ray (EDX) microanalysis [6]. It is important to know that for assessing the asbestos fibre burden a laboratory should be well experienced, have a standardised protocol and established reference values using the same method [6].

It is well known that chrysotile fibre numbers in the human lungs are lower than amphibole fibre numbers [8-11], although chrysotile was more frequently used in industry. This may be explained by the fact that chrysotile fibres tend to fray, are very flexible and disintegrate if exposed to acids [12], thus accelerated clearance of inhaled chrysotile fibres from the lungs sounds plausible [13]. Although the hazardous nature of amphibole fibres is not challenged $[8,14]$, the impact of chrysotile fibres is a matter of discussion $[15$, $16]$ and further research is needed [17].

Using diverse approaches, the persistence of asbestos fibres was investigated in experimental animal studies $[18,19]$. Investigations in humans were performed in asbestos miners in Canada $[8,14]$ and Australia [20] using analytical electron microscopy for fibre counts and conventional light microscopy for asbestos bodies. Asbestos concentrations found in the air in the working environment were related to fibre concentrations in lung tissue from autopsies. In another study autopsy samples from different patients with different periods of exposure cessation were compared [21]. All these studies suffer from the fact that they have no measured starting point of the asbestos fibre burden in the human lung tissue to compare their results to because of their cross-sectional design.

Instead of obtaining the half-lives of asbestos fibres by approximation and extrapolation $[8,14,20]$, the aim of the present study was to present data based on longitudinal intra-individual asbestos quantitation that was performed in the lung tissues of patients with asbestos diseases over intervals of several years. Our samples are taken from different tissue excisions from the same patient. The asbestos fibre burden has been counted by phase contrast microscopy routinely. Additionally an EDX analysis has been done to determine the asbestos fibre type.

\section{Material and methods}

The research was conducted according to the principles of the Declaration of Helsinki. Tissue removal occurred for medical reasons only or was carried out during autopsies requested by insurance companies. Relatives gave consent for all autopsies.

\section{Data screening}

The German Mesothelioma Register had 23955 datasets available with asbestos body counts performed during routine examinations of lung tissue samples or bronchoalveolar lavage (BAL) generated between 1987 and 2015. This data set was filtered for the following criteria (see also figure 1):

1) Results of asbestos body counts had to be available.

2) Earlier asbestos fibre burden from surgery or bronchoalveolar lavage had to be available.

3) The highest asbestos body count had to be above 500 fibres per gram of wet lung tissue. This filter ensured a relevant asbestos fibre burden to study a potential decrease of the asbestos concentration in the lung tissues. According to Roggli and Pratt [22], 200 asbestos bodies per gram of wet lung tissue correspond to two asbestos bodies in a histological specimen of $2 \times 2 \mathrm{~cm}$ at a $5 \mu \mathrm{m}$ section thickness. In Germany at least two asbestos bodies in a specimen of $1 \times 1 \mathrm{~cm}$ are required for the histological diagnosis 
FIGURE 1 Scheme of patient selection. Flow process chart showing how the register's database has been filtered. AB: asbestos bodies.

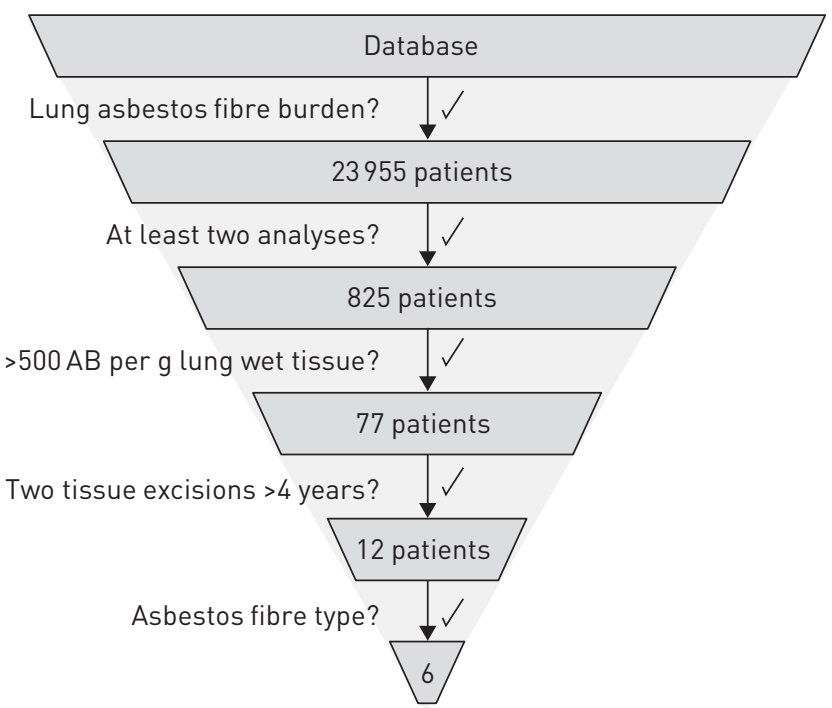

of asbestosis [23]. Given a section thickness of $2-4 \mu \mathrm{m}$ and two to four section specimens, this is equivalent to about 500 asbestos bodies per gram of wet lung tissue evaluated in lung dust analysis.

4) Analyses were from different tissue excisions with a time interval of at least 4 years.

\section{Histology}

Histopathological evaluation was performed by a pathologist who was highly experienced in the assessment of asbestos-induced changes. Asbestosis grading followed national [24] and international criteria $[6,25]$, i.e. primarily the Helsinki Criteria $[5,26]$.

\section{Analysis of the asbestos fibre burden in lung tissues or BAL}

Lung dust analysis was performed using established methods $[27,28]$ and is described in detail in the guideline on the diagnosis and medical appraisal of asbestos-associated diseases [23]. Briefly, formalin-fixed lung tissue samples or lavage fluid were digested using $12 \%$ sodium hypochlorite. The lysate was filtered through a $2 \mu \mathrm{m}$ Millipore nitrocellulose membrane and examined under a light microscope in a meandering pattern using $\times 200$ or $\times 400$ magnification and phase contrast. Fibres where analysed by transmitted and polarised light. Asbestos bodies, pseudo-asbestos bodies, asbestos fibres and structures with a non-identifiable core fibre were counted separately [29]. For comparability of the data, all counts provided in the original historical counting protocol were calculated to gram of wet lung tissue. In the following, all concentrations for asbestos bodies/asbestos fibres are per gram of wet lung tissue.

In view of the heterogeneous distribution of asbestos bodies in lung tissue [29], the content of asbestos fibres was determined at least in duplicate whenever sufficient tissue was available. In autopsy cases, analyses were performed in the upper and lower lobes of either side if possible. Care was taken to include healthy tumour-free lung parenchyma in the ashing analysis [28-30]. The sample with the highest asbestos body concentration determined was used in all cases [23].

\section{Electron microscopy}

Electron microscopic analysis was performed by field energy (FE)-SEM (Carl-Zeiss AG, Oberkochen, Germany), as described previously [31], and TEM (JEOL Ltd, Tokyo, Japan), both coupled with an EDX analysis system. For TEM the digestate was filtered through carbon-coated polycarbonate filters. Samples were cut out and placed onto a grid, then the filter was collapsed with chloroform and finally grids were evaporated using a second thin layer of carbon. We carried out qualitative analyses only for the purpose of identifying the nature of the asbestos fibres. This analysis included both fibres that were longer or shorter than $5 \mu \mathrm{m}$.

\section{Results}

The database research generated a collective of 12 patients with longitudinal data of the asbestos fibre burden. Tissue removal was due to a suspected tumour (58.3\%), to pleural thickening (16.7\%) or to lung fibrosis of unknown origin (8.3\%). In $16.7 \%$ of samples, a former BAL was available (table 1). The tissues were obtained in $50 \%$ from the right lung and in $25 \%$ from the left lung. No sampling site was given in $8.3 \%$, 
TABLE 1 Fibre analyses at surgery and autopsy in comparison with corresponding time intervals to exposure cessation

\begin{tabular}{|c|c|c|c|c|c|c|c|}
\hline Patient & $\begin{array}{l}\text { Years from last } \\
\text { exposure to } \\
\text { surgery }\end{array}$ & $\begin{array}{c}\text { Max } \\
A B / g \\
\text { FW surgery }\end{array}$ & $\begin{array}{c}\text { Years from last } \\
\text { exposure to } \\
\text { autopsy }\end{array}$ & $\begin{array}{c}\text { Max } \\
\text { AB/g } \\
\text { FW autopsy }\end{array}$ & $\begin{array}{l}\text { Years from } \\
\text { surgery to } \\
\text { autopsy }\end{array}$ & $\begin{array}{c}\text { Fibre type } \\
\text { [\% chrysotile] } \\
\text { FE-SEM }\end{array}$ & $\begin{array}{c}\text { Fibre type } \\
\text { [\% chrysotile] } \\
\text { TEM }\end{array}$ \\
\hline 2 & 9 & $1281^{\#}$ & 30 & 27921 & 21 & $35 \%$ & $30 \%$ \\
\hline 3 & $>6$ & 431 & $>14$ & 800 & 8 & $80 \%$ & $70 \%$ \\
\hline 4 & 20 & 1167 & 24 & 5347 & 4 & $95 \%$ & $90 \%$ \\
\hline 7 & 9 & 4528 & 16 & 5612 & 7 & ND & ND \\
\hline 8 & 9 & 6433 & 16 & 39121 & 7 & ND & ND \\
\hline 9 & $>12$ & 9750 & $>20$ & 53663 & 8 & ND & ND \\
\hline 10 & 24 & 1346 & 33 & 1269 & 9 & ND & ND \\
\hline 11 & 20 & $3.4^{\pi}$ & 33 & 1863 & 13 & $80 \%$ & $67 \%$ \\
\hline 12 & 29 & $10.3^{\pi}$ & 37 & 165347 & 8 & $85 \%$ & $90 \%$ \\
\hline
\end{tabular}

Occupational histories were obtained from clinicians or insurance. Approximations are indicated by $>$ (greater) if exact data are missing. In these cases exposure cessation was assumed to retirement age or the asbestos ban in Europe 1993 respectively as the latest. The actual end might have been earlier. Time intervals are also shown in figure 2, fibre analysis results referring to their corresponding time interval are illustrated in figure 3. Here only the highest asbestos body count from each patient is given. See supplementary material for details. Amphibole and chrysotile fibres were detected by energy-dispersive X-ray analysis for their elemental composition; here the percentage of chrysotile fibres is given after FE-SEM and TEM analysis. " : tissue with active tuberculosis, thus fibre count may be underestimated. ": Patients without lung tissue; values represent asbestos bodies per $\mathrm{mL}$ of bronchoalveolar lavage (BAL) fluid and were not considered for the calculation of mean and medians of the asbestos fibre burden. Max: maximum; AB: asbestos bodies; FW: fresh weight; ND: not done.

and $16.7 \%$ were from BAL. The first tissue excision/BAL with fibre analysis had been performed between 1987 and 2011. At this time the patients' last exposure to asbestos dated back 3-29 years (median 9.5 years).

Autopsies including fibre analysis for all patients were performed between 1996 and 2015 in the context of insurance enquiries. Age at death ranged from 62 to 82 years (median 76.5 years). Tumour recurrences were found in $25 \%$; in $8.3 \%$ a second primary tumour was diagnosed, and peritoneal mesothelioma had developed in another $8.3 \%$. In $16.7 \%$ asbestosis grade III was diagnosed, but grade I diseases dominated (58.3\%) (table 2). All patients with higher grade asbestoses had severe pleural complications, including extensive plaques with rounded or plate atelectases, diffuse pleural fibrosis, hyalinosis complicata, lung encasement and pleural thickening because of recurrent pleurisy. All patients died of their asbestos-related disease. The complete findings are listed in the supplementary material. Occupational history is listed in table 2. The time course of events is illustrated in figure 2 .

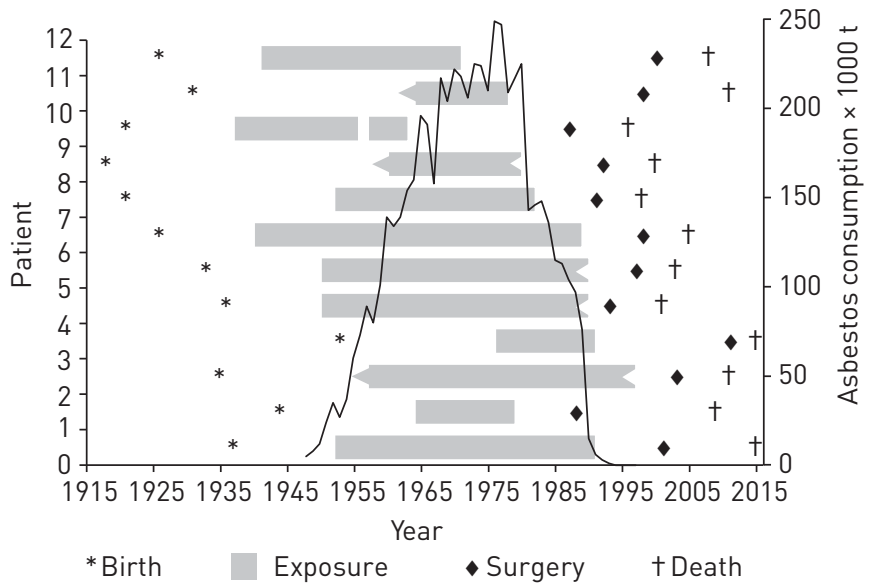

FIGURE 2 Time course of events. Illustration of birth, duration of exposure and time interval between tissue excisions/bronchoalveolar lavage (first fibre analysis from surgery, second fibre analysis from autopsy) in comparison to asbestos consumption in Germany. t: tons. Data source of asbestos consumption: [32]. 

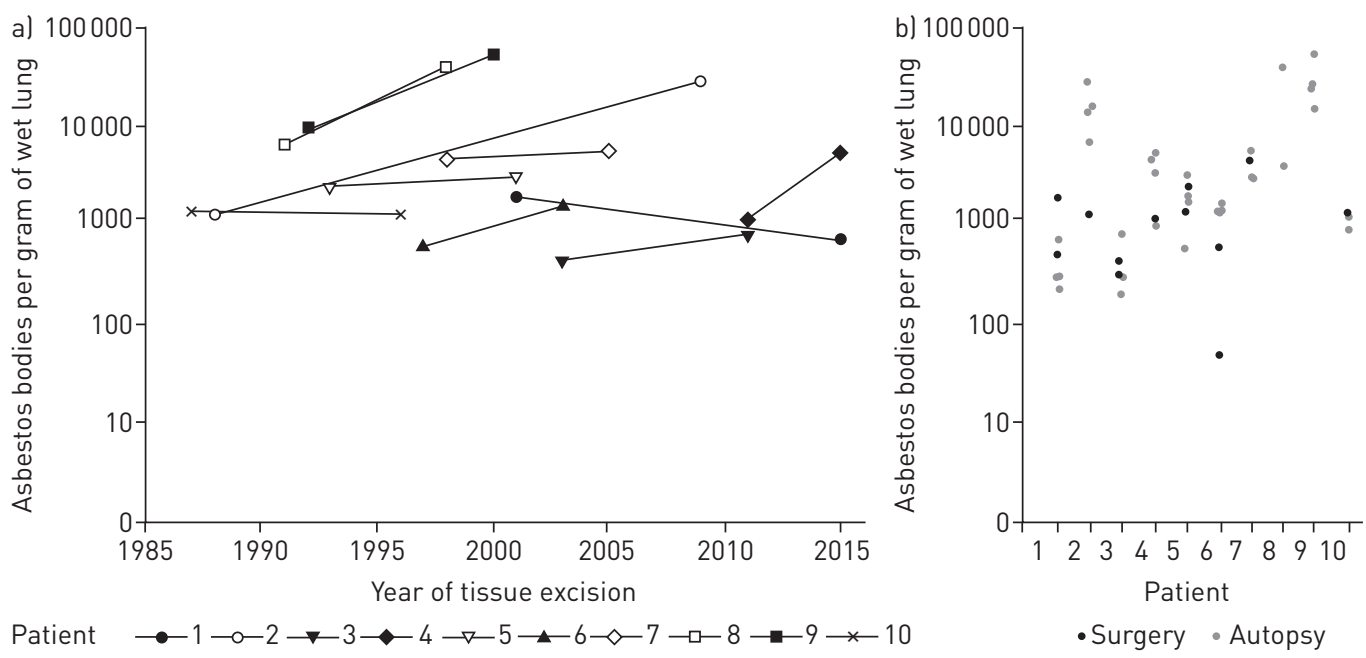

FIGURE 3 Results of fibre analyses at surgery (first tissue excision) and autopsy (second tissue excision) in relation to time from 10 patients. From these 10 patients the asbestos fibre burden of the lung has been determined from tissue both times. Two patients with fibre analysis from a bronchoalveolar lavage are not considered here. Illustrated are the results of the highest asbestos body count in relation to time (a) and all asbestos body counts from one patient's lungs separately (b). The corresponding time interval is already illustrated in figure 2 and listed in table 1 . It is easily seen in (b) that the counts from surgery are within the range of the counts from autopsy. For two patients the lower count from surgery tissue could be explained histologically (supplementary material). Patient 2 had tuberculosis in the first tissue and patient 6 had fibrosis with a multi-etiological clinical picture with an asbestos-dependent and an asbestos-independent component (see supplementary material for details).

The time period between tissue removals varied from 4 to 21 years (median 8 years). Taking the maximum count from each patient the first analysis produced a median of 1623 (431-9750), and the second analysis of 4269 (714-53663) asbestos bodies per gram of wet lung tissue (table 1). Taking all counts from one analysis into consideration the pulmonary asbestos body concentration showed a median of 1313 (49-9750) in the first tissue excision and 2018 (198-53663) in the second one (figure 3). The median pulmonary asbestos fibre concentration (total of asbestos bodies and bare fibres ) was 1623 at surgery and 2202 at autopsy (supplementary material). For the whole group there was no relevant decrease in the asbestos fibre burden over the investigated time ( $p=0.9863$, one-sided Wilcoxon signed rank test).

TABLE 2 Data of patients and pathologic autopsy findings

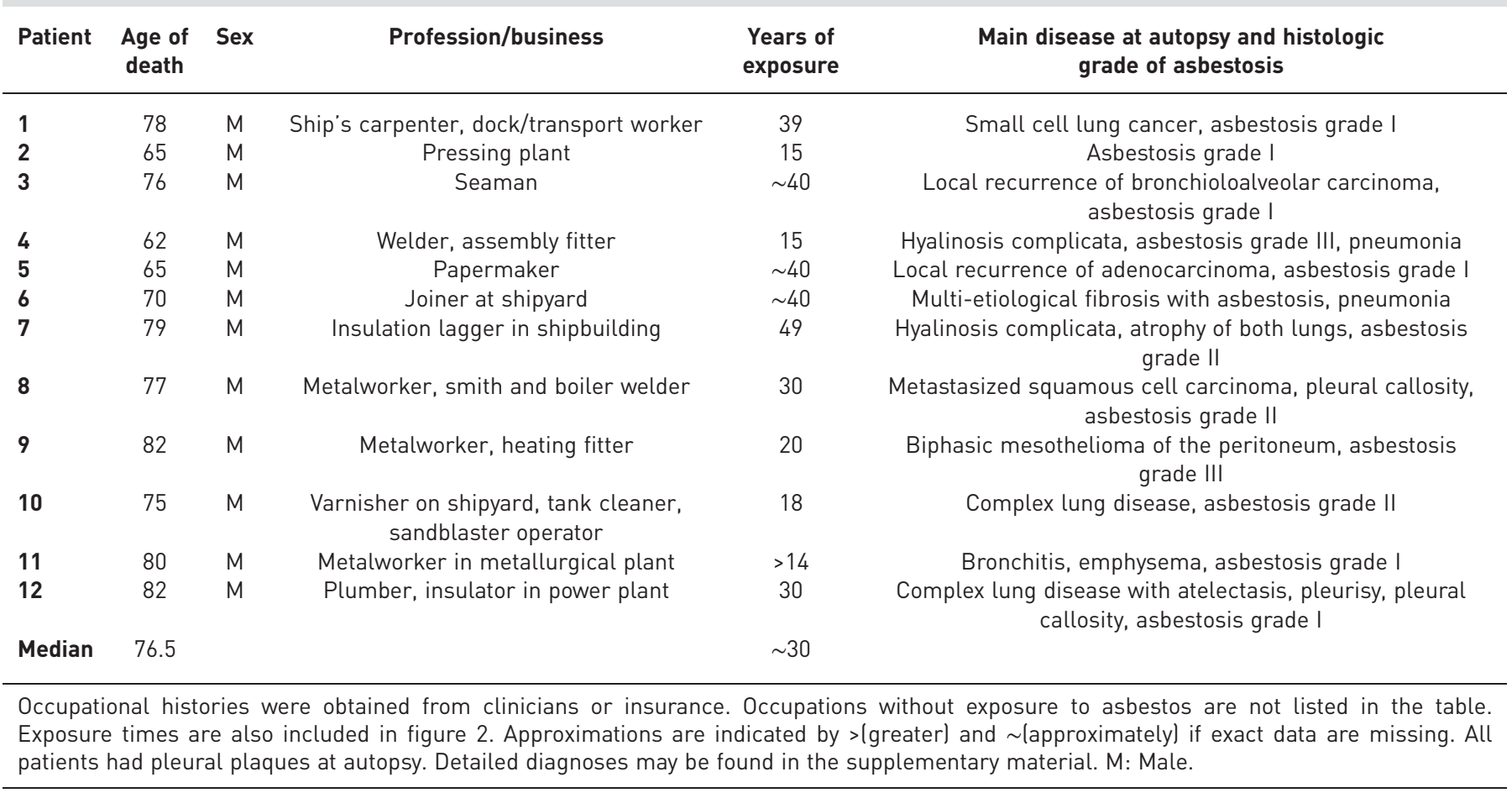



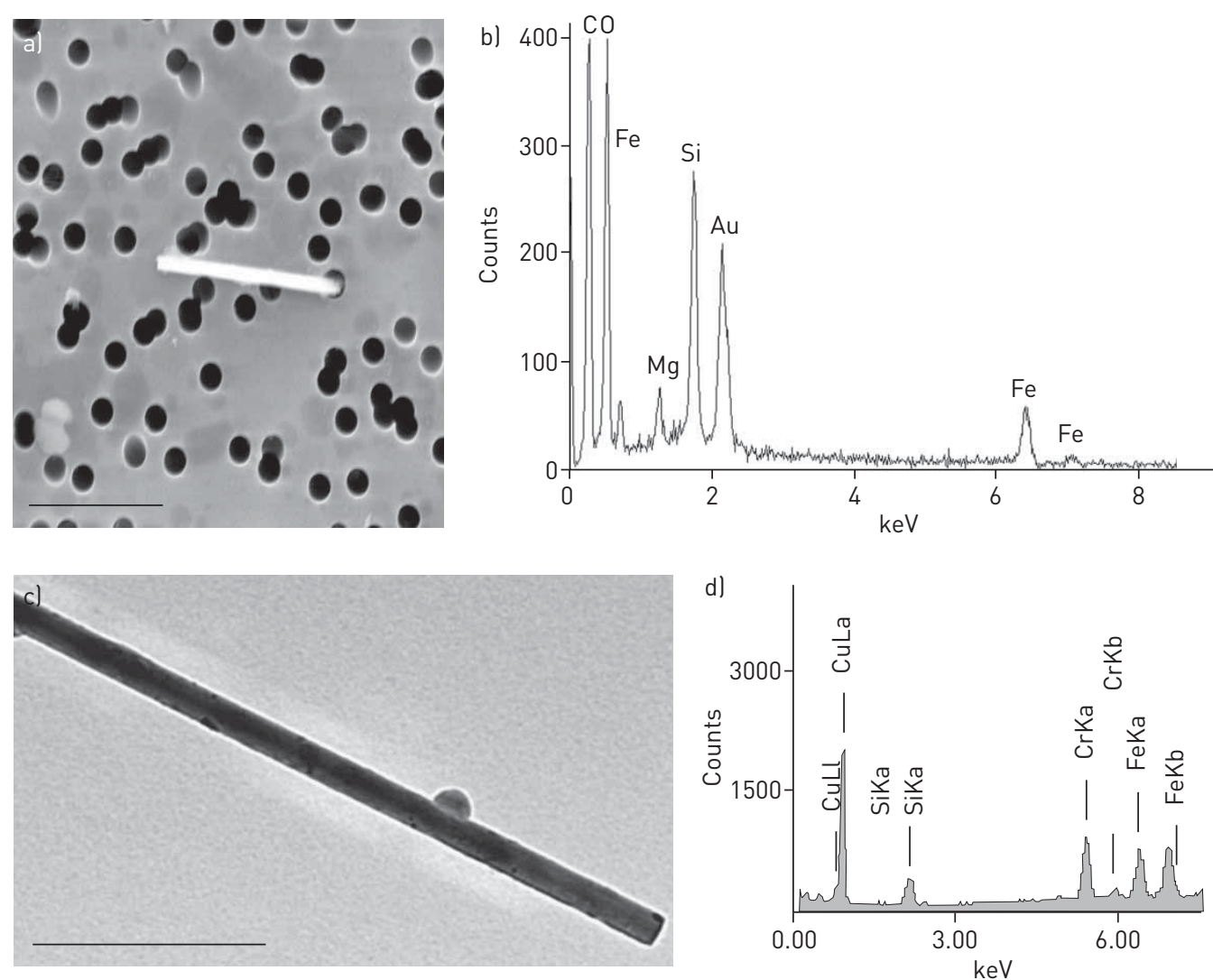

FIGURE 4 Amphibole-fibre with the corresponding spectra obtained by energy-dispersive X-ray (EDX) analysis. a) Field emission scanning electron microscopic image from an edged fibre extracted from lung tissue of an asbestos exposed patient. The fibre is greater than $5 \mu \mathrm{m}$ and thinner than $3 \mu \mathrm{m}$. 10000-fold magnification. b) The EDX spectra of the fibre with magnesium (Mg), silicon (Si) and iron (Fe). The elemental composition and morphology of the fibre is typical for amphibole. The gold (Au) signal originates from the filter and should be ignored. c) Transmission electron microscopy image of an amphibole fibre with residual macrophage body and the corresponding EDX spectra (d). The copper $(\mathrm{Cu})$ signal originates from the grid and should be ignored.

In only $8 \%$ the result of the asbestos body count from autopsy was below the sample obtained during surgery. Here, amphibole asbestos was the dominant fibre type at autopsy (table 1, figure 4).

Electron microscopic analyses of all available samples were done $(n=6)$. In $33.3 \%$ of samples mainly amphibole was found by FE-SEM/EDX analysis (65\% to 90\%) (table 1, figure 4), but in the other 66.7\% chrysotile was the dominant asbestos fibre (at different percentages of $80 \%$ to $95 \%$ ) (table 1, figure 5). When the fibre analysis was done by TEM, the percentages varied a little bit but the statement was confirmed (table 1). The proportion of chrysotile fibres did not correlate with the duration of asbestos exposure ( $\mathrm{p}=0.65$; rho -0.24 , Spearman's rank correlation) or with the time interval between last asbestos exposure and tissue analyses ( $\mathrm{p}=0.74$; rho 0.18 Spearman's rank test).

\section{Discussion}

Resection of lung tissue for scientific or insurance purposes alone is not admissible and ethically not justifiable [28]. It is thus impossible to study the asbestos fibre burden in the human lung in vivo within a prospective systematic study.

This study is the first to present data from intra-individual longitudinal asbestos fibre analyses that were obtained by means of standardised analytical procedures in the lung tissues of patients with previous asbestos exposure at intervals of several years (figure 2). Our results show that asbestos continues to be demonstrable in human lungs, that also chrysotile can be identified after many years, and that there is no significant reduction of asbestos fibre concentrations in lung tissues over time after exposure cessation.

The unique benefit of the data presented here is to have a measured starting point of the asbestos fibre burden of the human lung tissue to compare later findings with. Earlier studies defined biopersistence of asbestos in lung tissue after animal experiments $[18,19,33]$ or hypothetical models that estimated baseline 

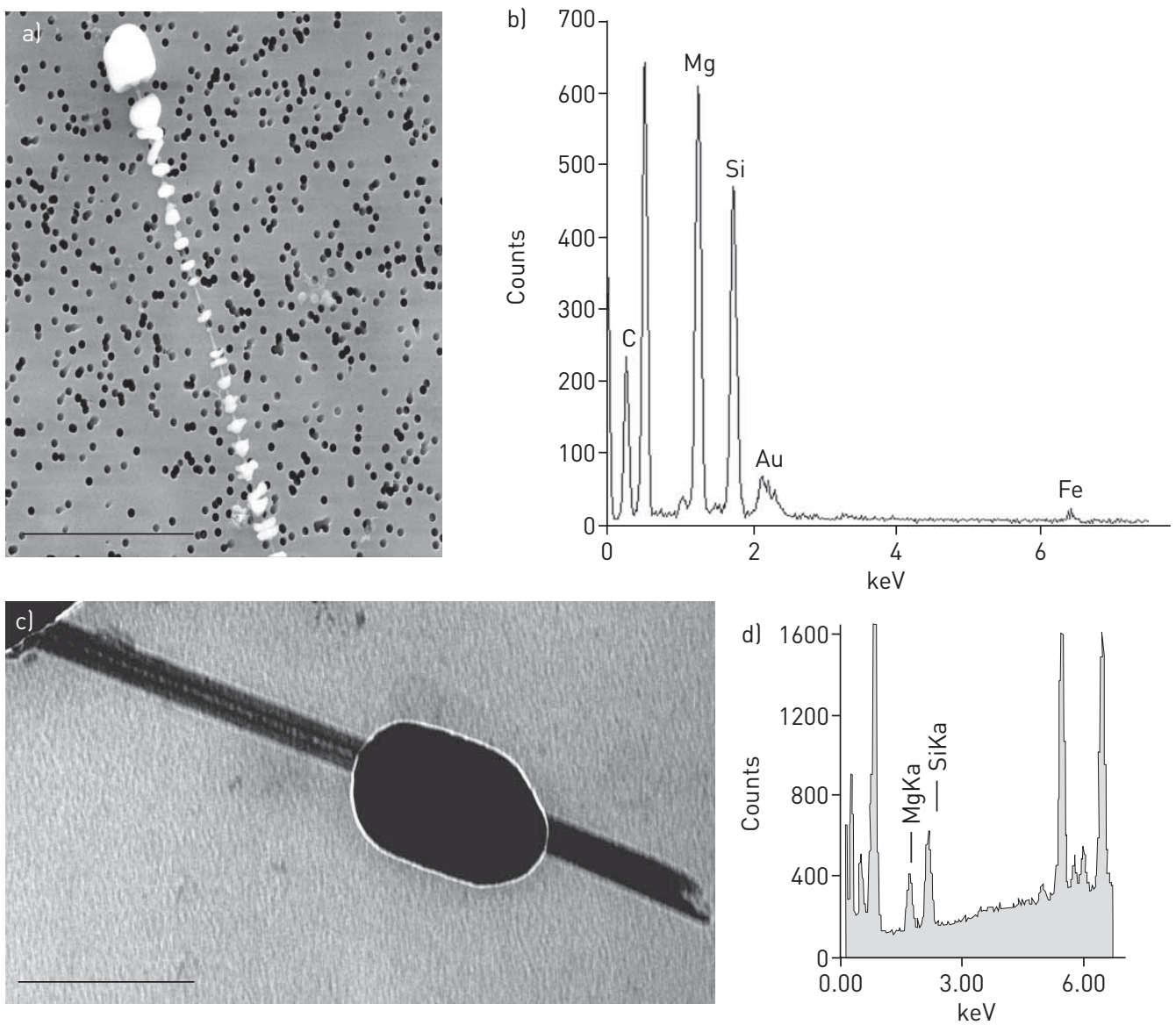

FIGURE 5 Chrysotile fibre with the corresponding spectra obtained by energy-dispersive X-ray analysis (EDX). a) Field emission scanning electron microscopic image from a markedly thin fibre extracted from lung tissue of an asbestos exposed patient. The fibre is more than $10 \mu \mathrm{m}$ in length with a shell of ferruginous bodies. 6000 -fold magnification. b) The EDX spectra of the denudated part of the asbestos body with magnesium $(\mathrm{Mg})$, silicon (Si) and iron (Fe). The elemental composition and morphology of the fibre is typical for chrysotile. The gold (Au) signal originates from the filter and should be ignored. c) Transmission electron microscopy image of a chrysotile fibre and the corresponding EDX spectra (d).

exposure concentrations from measuring airborne asbestos concentrations at workplaces; these data were then associated with autopsy results $[8,10,14,20]$. Other authors compared fibre counts from different time periods $[34,35]$. Our samples have been analysed in a quantitative way by phase contrast microscopy in the same laboratory using the same method. The laboratory has had experience in this method since 1987.

Individual asbestos concentrations in lung tissue remained stable across intervals of 4-21 years between the two tissue excisions. Other authors reported a reduction of the asbestos fibre burden in lung tissue over 25 years of investigation [34], but were easily able to explain this with a reduction in exposure because of the 1972 asbestos ban for insulating products in the USA. In contrast to other authors, the analyses reported in this manuscript concerned one and the same patients. Hence, past asbestos exposure was identical for both analyses, but occurred much earlier in each case (figure 2). Thus, exposure is not a confounder in the present data.

Assuming a variation by a factor of seven to 10 for asbestos concentrations within a human lung [29] definitely places the asbestos fibre concentrations in $90 \%$ of our patients within the range of the samples that had been analysed 4-21 years earlier (figure 3 ). This ties in very well with earlier reports of latency periods from 10 to 60 years of asbestos-related diseases, which are considered to develop typically while asbestos is present [36].

In some patients fibre numbers obtained after autopsies were higher than those after surgery. This may be explained by the well-known requirement to evaluate several tissue samples of one lung because of the heterogeneous distribution of asbestos bodies in lung tissue $[6,26,29]$. Such multiple tissue samples that are suitable for fibre analyses can be collected only by autopsies. Tissue from surgery is of limited size or from the side of the tumour in cases where a tumour is present. The contralateral lobe is available from 
autopsy tissue, as recommended in the guidelines $[6,26]$; also, the lower lobe is available, which commonly contains higher fibre counts. According to the German AMWF guideline [23], we took the highest count as the result in table 1 but relativised the results in figure 3, when all counts are considered. With restriction of tissue availability the asbestoses were still clearly confirmed from surgery tissue.

Light microscopy with phase contrast only reveals asbestos fibres with a thickness exceeding $0.2 \mu \mathrm{m}$. However, the result of light microscopic counts are a good measure for the overall asbestos fibre burden of the lung tissue under investigation and may well serve for comparative analyses [30].

Unlike other authors [28, 29], we did not pool samples but analysed each of them separately. This approach affords the opportunity of interpreting the asbestos concentrations in direct relation to histology. Moreover, focal accumulations in a pulmonary lobe can also be detected and be properly assessed because a given sample from one lobe will not be diluted by samples from other lobes that contain lower concentrations. Asbestos-related changes of the lung have been shown to predominantly affect the lower lobe; this will only be reflected adequately when different samples are analysed separately.

In $16.7 \%$ where contact with asbestos dated back to between 20 and 29 years, the first lung dust analyses had been performed on BAL samples. They showed elevated asbestos fibre burden that had been confirmed at autopsies carried out 8-13 years later. BAL is indeed useful in establishing earlier asbestos exposure even if it dates back a very long time $[35,37,38]$. This was once more corroborated in the present study.

A qualitative fibre analysis by EDX analysis demonstrated chrysotile as the main fibre in most tissue samples $(66.7 \%)$ with asbestos exposure cessation dating back up to 37 years. This is in line with the results of other authors who found mainly chrysotile in lungs of German patients [9]. In contrast, only amphiboles could be detected in cases with pneumoconiosis in the UK [11], but chrysotile concentrations showed no elevation compared with a control group. The same applies to a study conducted in North America [39], where again only amphibole asbestos was found in mesothelioma patients. On the other hand, an increase in asbestos-related diseases has been observed in miners and millers in Canada, although exposure involved only chrysotile fibres. The fibres were demonstrable in lung tissue over several years $[8,14]$. An explanation for this might be qualitative differences in regional asbestos exposure. Possibly, the resident times in lung tissues differ with differing origin and shape of chrysotile fibres.

Different techniques of tissue preparation and fibre analysis might be another explanation for different findings in different studies. In lung dust analysis, only asbestos can be detected that has been extracted from tissue and which is not lost as a function of this process. Chrysotile is dissolved completely when acids are applied [12]. Fibres may also be destroyed by uncontrolled use of ultrasound or may be lost during multiple steps of centrifugation [28]. For electron microscopic analysis main parts of the body of the fibre are destroyed to access the core fibre. The strong beam needed for TEM might also destroy the asbestos fibre leading to significant identification errors [40]. In our routine examinations great importance is set to keep losses at the lowest possible level when processing the samples and centrifugation is not used. To analyse the core fibre we used FE-SEM, which has a higher resolution than SEM; there is also less damage to the fibre than with TEM. As TEM is considered to be the gold standard for fibre analysis $[6,26]$, we also applied this method to the available samples confirming the FE-SEM data.

Electron microscopic analyses of fibre types in this study were performed in autoptic tissues. The total asbestos fibre burden of the lungs had remained constant across the complete period of investigations. Even at the time of the first tissue/BAL sampling, the patients had no longer been exposed to asbestos. Thus it is clear that there has been no relevant change in the ratio of amphibole to chrysotile fibres and that the chrysotile concentration has remained stable over the investigation period of 4-21 years. This also explains why we could not identify a correlation between the chrysotile content and the time interval from last exposure or the duration of exposure. Our results perfectly correlate to data published by CHURG and DEPAOLI [21], who found that the ratio of chrysotile to amphibole (in this case tremolite) concentration did not change with time by comparing two sets of patients with a short and a long time interval to exposure cessation.

Since the asbestos fibre concentrations had remained stable in the patients investigated, our data indicate that the well-known and scientifically recognised reduction of chrysotile fibres in human lung tissue $[8,11,39]$ must have occurred at a very early time point. At the time of the first tissue sampling the last asbestos exposure had ended 3-29 years ago (median 9.5 years). This means that the reduction of chrysotile fibres must have occurred within this time span. Our study again confirms what has been postulated by CHURG and DEPAOLI [21]: both studies "imply that the failure of chrysotile to accumulate in human lungs reflects events that occur early after exposure rather than long-term clearance mechanisms" 
and is best explained by the natural defence mechanisms of the human lung, e.g. mucociliary clearance in the bronchi and expectoration, and possibly acid hydrolysis by lysosomes. This is in line with the half-life times of a few weeks to several months found by Churg for chrysotile in human lung tissues [8]. Apart from that, the type and geometry of fibres seem to play a part. Certain chrysotile fibres which, like amphibole fibres, have successfully overcome the defence mechanisms of the lung and penetrated deeply into the alveoli can no longer be eliminated, and are therefore traceable in the human lung for many years.

Owing to their extreme biopersistence, the fibres cannot be biologically reduced by the lung macrophages. The macrophages die and form the typical asbestos bodies [7, 33]. By their pin-like/acicular structure the fibres are prone to get caught in the alveoli of the lung parenchyma, so that clearing them from the system cannot be achieved. The human lung has no defence mechanisms that could eliminate the invasive fibres from the alveoli of the lung. Asbestos fibres, therefore, remain in the lung where their sustained presence causes lung disease. Continuous irritation of the tissue results in chronic inflammation to which the tissue responds by scar formation [36]. It is not only the amphibole fibres that can be identified in lung tissue over many years, but also chrysotile fibres, as is typical of pneumoconiosis due to asbestos fibres.

The hazardous nature of chrysotile asbestos is under discussion. The answer to this question is of high impact for physicians, toxicologists and occupational as well as environmental risk assessment. Our unique data experimentally confirmed the well-known characteristics of the asbestos fibres (asbestos in ancient Greek $\alpha \sigma \beta \varepsilon \sigma \tau$ os=imperishable) for individual human lungs in vivo over many years. Overall, this study very clearly demonstrates high biopersistence of not only amphibole but also chrysotile asbestos in the human lung and thus gives mechanistic explanations for the toxicity of the fibre and the long latency period of asbestos related diseases.

\section{Acknowledgements}

We thank Berlinda Verdoodt for critical review of the manuscript.

\section{References}

1 Gilham C, Rake C, Burdett G, et al. Pleural mesothelioma and lung cancer risks in relation to occupational history and asbestos lung burden. Occup Environ Med 2016; 73: 290-299.

2 Yusa T, Hiroshima K, Sakai F, et al. Significant relationship between the extent of pleural plaques and pulmonary asbestos body concentration in lung cancer patients with occupational asbestos exposure. Am J Ind Med 2015; 58: $444-455$.

3 Attanoos RL, Alchami FS, Pooley FD, et al. Usual interstitial pneumonia in asbestos-exposed cohorts - concurrent idiopathic pulmonary fibrosis or atypical asbestosis? Histopathology 2016; 69: 492-498.

4 Monsó E, Tura JM, Pujadas J, et al. Lung dust content in idiopathic pulmonary fibrosis: a study with scanning electron microscopy and energy dispersive x ray analysis. Br J Ind Med 1991; 48: 327-331.

5 Henderson D, Rantanen J, Barnhart S, et al. Asbestos, asbestosis and cancer: the Helsinki criteria for diagnosis and attribution. Scand J Work Environ Health 1997; 23: 311-316.

6 Roggli VL, Gibbs AR, Attanoos R, et al. Pathology of asbestosis: an update of the diagnostic criteria. Report of the Asbestosis Committee of the College of American Pathologists and Pulmonary Pathology Society. Arch Pathol Lab Med 2010; 134: 462-480.

7 Cooke WE. Fibrosis of the lungs due to the inhalation of asbestos dust. Br Med J 1924; 2: 140-142, 147.

8 Churg A. Deposition and clearance of chrysotile asbestos. Ann Occup Hyg 1994; 38: 625-633.

9 Friedrichs KH, Brockmann M, Fischer M, et al. Electron microscopy analysis of mineral fibers in human lung tissue. Am J Ind Med 1992; 22: 49-58.

10 Rasmuson JO, Roggli VL, Boelter FW, et al. Cumulative retrospective exposure assessment (REA) as a predictor of amphibole asbestos lung burden: validation procedures and results for industrial hygiene and pathology estimates. Inhal Toxicol 2014; 26: 1-13.

11 Wagner JC, Pooley FD, Berry G, et al. A pathological and mineralogical study of asbestos-related deaths in the United Kingdom in 1977. Ann Occup Hyg 1982; 26: 423-431.

12 Turci F, Tomatis M, Mantegna S, et al. A new approach to the decontamination of asbestos-polluted waters by treatment with oxalic acid under power ultrasound. Ultrason Sonochem 2008; 15: 420-427.

13 Sporn TA. Mineralogy of asbestos. In: Tannapfel A, ed. Malignant Mesothelioma. Heidelberg, Springer-Verlag, 2011: pp. 1-11.

14 Finkelstein MM, Dufresne A. Inferences on the kinetics of asbestos deposition and clearance among chrysotile miners and millers. Am J Ind Med 1999; 35: 401-412.

15 Bernstein D, Dunnigan J, Hesterberg T, et al. Health risk of chrysotile revisited. Crit Rev Toxicol 2013; 43: 154-183.

16 LaDou J, Castleman B, Frank A, et al. The case for a global ban on asbestos. Environ Health Perspect 2010; 118: 897-901.

17 Gwinn MR, DeVoney D, Jarabek AM, et al. Meeting report: mode(s) of action of asbestos and related mineral fibers. Environ Health Perspect 2011; 119: 1806-1810.

18 Bernstein DM, Cevalier J, Smith P. Comparison of Calidria chrysotile asbestos to pure tremolite: final results of the inhalation biopersistence and histopathology examination following shortterm exposure. Inhal Toxicol 2005; 17: 427-449.

19 Muhle H, Bellmann B, Pott F. Comparative investigations of the biodurability of mineral fibres in the rat lung. Environ Health Perspect 1994; 102: Suppl 5, 163-168. 

workers from Wittenoom Gorge, W. Australia. Am I Ind Med 1996; 30: 579-587.

21 Churg A, DePaoli L. Clearance of chrysotile asbestos from human lung. Exp Lung Res 1988; 14: 567-574.

22 Roggli VL, Pratt PC. Numbers of asbestos bodies on iron-stained tissue sections in relation to asbestos body counts in lung tissue digests. Hum Pathol 1983; 14: 355-361.

23 AWMF 2010. Leitlinie "Diagnostik und Begutachtung asbestbedingter Berufskrankheiten. Interdisziplinäre S2-Leitlinie der Deutschen Gesellschaft für Pneumologie und Beatmungsmedizin und der Deutschen Gesellschaft für Arbeitsmedizin und Umweltmedizin". AWMF Registernummer 002-038; 2010. [Diagnostics and Expert Opinion of Asbestos-induced Occupational Diseases. Interdisciplinary Guideline of the German Respiratory Society and the German Society of Occupational and Environmental Medicine, in German] German Respiratory Society, German Society of Occupational and Environmental Medicine. Available from: www.awmf.org/uploads/ tx_szleitlinien/002-0381_S2k-Diagnostik_Begutachtung_asbestbedingter_Berufskrankheiten_2010-abgelaufen.pdf

24 Heitz P. Neue Definitionen der Minimalasbestose [New definitions of minimal asbestosis]. Dtsch Ärztebl 1997; 94: A975.

25 Craighead JE, Abraham JL, Churg A, et al. The pathology of asbestos-associated diseases of the lungs and pleural cavities: diagnostic criteria and proposed grading schema. Report of the Pneumoconiosis Committee of the College of American Pathologists and the National Institute for Occupational Safety and Health. Arch Pathol Lab Med 1982; 106: 544-596.

26 Wolff H, Vehmas T, Oksa P, et al. Asbestos, asbestosis, and cancer, the Helsinki criteria for diagnosis and attribution 2014: recommendations. Scand J Work Environ Health 2015; 41: 5-15.

27 Eitner F, Otto H. Zur Dignität von Asbestkörperzählungen im Lungengewebe [On the dignity of asbestos body counts in lung tissue]. Arbeitsmed Sozialmed Präventivmed 1984; 19: 1-5.

28 De Vuyst P, Karjalainen A, Dumortier P, et al. Guidelines for mineral fibre analyses in biological samples: report of the ERS Working Group. European Respiratory Society Eur Respir J 1998; 11: 1416-1426.

29 Gibbs AR, Pooley FD. Analysis and interpretation of inorganic mineral particles in "lung" tissues. Thorax 1996; 51: $327-334$.

30 Ashcroft T, Heppeleston AG. The optical and electron microscopic determination of pulmonary asbestos fibre concentration and its relation to the human pathological reaction. J Clin Pathol 1973; 26: 224-234.

31 BIA. BIA-Arbeitsmappe "Bestimmung von anorganischen Fasern im menschlichen Lungengewebe". BIA-Arbeitsmappe 26. Lfg 26. III/01;2001. [FE-SEM Workbook: Determination of Inorganic Fibres in Human Lung Tissue] https://www.ifa-arbeitsmappedigital.de/IFA-AM_7489-1-1.

32 DGUV. BK-Report 1/2013. Faserjahre. http://www.dguv.de/ifa/publikationen/reports-download/reports-2013/bkreport-1-2013/index.jsp

33 Gandolfi NB, Gualtieri AF, Pollastri S, et al. Assessment of asbestos body formation by high resolution FEG-SEM after exposure of Sprague-Dawley rats to chrysotile, crocidolite, or erionite. J Hazard Mater 2016; 306: 95-104.

34 Roggli VL, Vollmer RT. Twenty-five years of fiber analysis: what have we learned? Hum Pathol 2008; 39 : 307-315.

35 Nuyts V, Vanhooren H, Begyn S, et al. Asbestos bodies in bronchoalveolar lavage in the 21st century: a time-trend analysis in a clinical population. Occup Environ Med 2017; 74: 59-65.

36 Konietzko N, Teschler H. Asbest und Lunge [Asbestos and the lung]. Darmstadt, Steinkopff Verlag, 1992.

37 Cordeiro CR, Jones JC, Alfaro T, et al. Broncho-alveolar lavage in occupational lung diseases. Semin Respir Crit Care Med 2007; 28: 504-513.

38 Teschler H, Hoheisel G, Fischer M, et al. [The content of asbestos bodies in the bronchoalveolar fluid as a parameter of an increased pulmonary asbestos load]. Dtsch Med Wochenschr 1993; 118: 1749-1754.

39 McDonald AD, McDonald JC, Pooley FD. Mineral fibre content of lung in mesothelial tumours in North America. Ann Occup Hyg 1982; 26: 417-422.

40 Martin J, Beauparlant M, Sauvé S, et al. Effect of temperature on beam damage of asbestos fibers in the transmission electron microscope (TEM) at $100 \mathrm{kV}$. Micron 2017; 94: 26-36. 